\title{
Constructing China 's Index of Sustainable Economic Welfare(ISEW) Lei Tang ${ }^{1, a^{*}}$
}

${ }^{1}$ School of Economics and Commerce of South China University of Technology, Guangzhou, Guangdong,China

aTangLei2017scut@outlook.com

Keywords: Limitation of GDP, Index of Sustainable Economic Welfare, Sustainability.

\begin{abstract}
China is in a critical period of comprehensively building a well-off society. How to make economic development to benefit the public and improve people's livelihood has become one of the main tasks of social construction in China. Therefore, The construction of China's index of sustainable economic welfare will be of great practical significance.
\end{abstract}

\section{构建中国可持续经济福利指数}

\author{
唐蕾 $1, \mathrm{a}^{*}$ \\ 1华南理工大学经济与贸易学院, 广州, 广东, 中国 \\ aTangLei2017scut@outlook.com
}

关键词: GDP缺陷；可持续经济福利指数；可持续性

中文摘要. 当前我国正处在全面建设小康社会的决胜期。如何使经济发展惠及大众、保障与 改善民生已成为我国社会建设的主要任务之一。在这一背景下，构建中国可持续经济福利指 数衡量经济福利状况将具有重要的现实意义。

\section{1. 引言及文献综述}

发展经济的最终目的是提高人民经济福利、让人民幸福。改革开放三十多年来，我国经 济以令人瞩目的速度迅速增长。目前, 我国GDP总量已经超越日本, 成为全球第二大经济体。 然而, 迅速的经济增长却无法掩盖增长的价值缺失, 片面地追求GDP增长而忽视经济增长的 质量与效益。资源过度消耗、环境污染、贫富差距不断扩大、居民消费率持续下降等环境、 社会问题日益凸现，经济增长已逐渐失去其应有的意义。过去以来，人们一直将GDP作为衡 量经济福利的指标，但随着世界寻求可持续发展、推行生态文明建设的步伐，人们也意识到 GDP作为福利度量指标的不足。其缺陷主要体现在：（1）GDP作为 “经济加总” 指标，无法 区分对福利有益和有害的经济行为，把一些对经济无益的防护性支出也核算在内，如家庭通 勤支出、交通事故成本等; (2) GDP没有全面覆盖对福利有益的活动, 如家务劳动等非市场 行为; (3) GDP没有考虑社会与环境问题, 如社会收入差距过大、环境污染与破坏。由于这 些缺陷, 显然GDP不为一个合适的福利度量指标。但是保障与改善民生已成为我国社会建设 的重心，因此构建我国的福利度量指标检验我国经济发展是否惠及大众、引导经济政策朝着 增进社会福利的方向调整、促进经济转型升级已刻不容缓。

国际上早已对经济福利展开研究, 提出许多衡量经济福利的指标。其中, 世界银行经济 学家Herman E. Daly与John B. Cobb于1989年提出的可持续经济福利指数（Index of Sustainable Economic Welfare, 以下简称ISEW）不仅考虑GDP衡量的 “经典” 物质福利, 还考虑了非市 
场活动、防护性支出、环境损害等方面, 既反映经济增长的可持续性又体现经济福利的变化, 因此得到大多数学者接受与应用。目前, 学者已利用ISEW对美国、德国、英国、澳大利亚、 比利时、意大利、泰国、智利等国家的经济福利进行研究。这些研究普遍显示当经济增长到 一定程度后，福利不会随着GDP的增长而增加且二者之间的绝对差距也越来越大。例如

Engelbert Stockhammer、Harald Hochreiter等利用ISEW对澳大利亚1955-1992年的经济福利进 行研究。其研究结果显示澳大利亚的经济增长并没有处在可持续发展路径上, 随着资源消耗、 长期环境损害等问题引起的负面作用逐渐显现，澳大利亚的福利水平从1980年就开始停止增 长甚至随着GDP增加而下降且二者之间的差距也越来越大。

\section{2. 可持续经济福利指数}

ISEW的核算体现了经济增长的可持续性与福利的变化。ISEW以加权消费支出作为核算 的基础，从社会、政府、环境三个方面共20个项目进行综合调整计算，核算总方法是ISEW等 于加权消费支出、社会行为净收益与政府行为净收益三个项目之和，再减去环境成本。

\section{1 核算基础}

加权消费支出。加权消费支出是经过收入不均等调整后的个人消费支出。庇古最早研究 收入分配对福利的影响, 认为由于货币边际效用递减, 收入增长带来贫困家庭福利增加量大 于同等收入降低引起富裕家庭福利减少量，因此财富在社会不同个体之间的分配状态会影响 不同成员的福利水平。大量的理论与经验研究都显示收入分配不均等加剧不利于经济福利增 长。

\section{2 社会行为净收益}

该部分核算对福利有益的项目有：家庭劳务价值、净资本增加、耐用消费品收益与成本。 对福利不利的项目有: 交通通勤支出、家庭污染治理支出、家庭教育与医疗防御支出、交通 事故成本、净外债变化。洗衣、做饭、照看子女与老人等这类有益的家庭劳动, 由于没在市 场上直接交易而被忽略，但这些劳动却明显地对居民福利有正向影响，因此应将这部分纳入 福利核算范围。净资本增长可以补偿人口与劳动力增长引起资本存量的变化, 反映福利增长 的可持续性。家庭耐用消费品与一般物品相比, 其服务年限较长、在使用期限内持续为家庭 提供服务。GDP直接将购买耐用消费品成本作为其服务价值, 这样不能真实体现出耐用消费 品的效用。ISEW则根据耐用消费品的特征分别核算其成本与服务价值, 正确地反映了耐用消 费品带来的损益。净外债变化可以衡量一个国家经济的发展对外国资本的依赖程度、核算福 利时扣除这部分是为了准确度量国家或地区的自我发展能力。交通通勤支出、家庭污染治理 支出、家庭教育与医疗支出、交通事故成本都属于防护性支出, ISEW将其作为成本扣除。如 家庭购买净水器、空气净化器等家用污染治理设备, 虽然这部分支出是经济支出, 但它本质 上属于人们出于对健康的考虑而发生的无奈支出, 因此不将此部分支出作为增加福利的项目。

\section{3 政府行为净收益}

该部分核算项目有公共教育与医疗支出，高速公路与街道服务价值。教育、医疗水平的 提高是社会福利提升的重要体现。政府教育与医疗的财政支出是属于积极性支出, 政府增加 教育、医疗投入可以提高教育水平、增加教育普及度以及改善就医环境等改善社会经济福利。 高速公路与街道服务投入是属于政府基础建设支出，可以提高社会整体的经济福利。除此之 外, 其它政府支出本质上都具有防护性不为经济产出、是政府为了防止社会福利下降而发生 的维持国家正常运行与安全、进行环境治理等遗憾性支出，并不能增加社会净福利。

\section{4 环境成本}

该账户核算项目有空气污染损失、水污染损失、噪音污染损失、湿地损失、耕地损失、 不可再生资源的过度消耗、长期环境损害、臭氧减少成本。GDP作为福利核算指标最大的诟 
病就是没有考虑经济增长对环境影响。有些经济活动对生态环境造成了破坏减少社会福利水 平, 而GDP却仍将其作为收益核算。用ISEW进行福利核算时, 其充分考虑了经济活动与环境 之间的相互影响，衡量了经济增长的可持续性。水资源、大气资源既为人类提供赖以生存的 洁净的饮用水与新鲜的空气，更有巨大的经济价值。三废污染不仅造成生态环境长期破坏、 更对人类的健康造成极大的损害。湿地、耕地提供人类生存的基本资源与条件，两者都既具 有巨大的环境效益, 又能为人类的生产、生活提供丰富的资源。因此，在考察经济福利时要 将这些项目考虑进来。煤、石油等可耗竭资源的开采使用, 的确能够给当代人带来福利的增 加，但考虑到资源的不可再生性、过度消耗资源只是将未来的经济福利提前预支而已，不利 于福利的可持续性, 因此ISEW的核算中将此部分扣除。长期环境损害是考量温室气体的排放 对全球气候产生的长期影响, 温室气体对大自然的影响是一个不断累积的过程, 具有长期性 和持久性。臭氧是地球的保护伞、臭氧减少会对人类健康、生态以及环境等各方面产生不利 的影响，因此核算福利时出于福利的可持续性考量也应将此部分扣除。

\section{3. 构建中国可持续福利指标存在的困难}

\section{1 传统观念转变困难}

“一切以GDP为中心” 这种错误思想在我国已形成了较长时期, 一些地方政府依旧盲目 地将追求GDP数值增长作为一切的工作核心。这不仅会使得政府不因地制宜寻求经济的可持 续发展方式, 盲目地寻求粗放式经济增长造成资源浪费、环境污染, 更会导致政府工作重心 的偏移忽视民生的建设，从而使得福利核算体系构建、推行十分困难。

\section{2 缺乏相应的制度建设}

虽然ISEW理论基础与实际应用都在国外发展得比较成熟, 但在国内却并没有真正引起重 视、起到应有的作用。外来指标的本土化应用固然存在一定困难，但根本原因在于我国没有 建立相应的保障制度与核算制度作为实施的基础。没有强制性核算要求，我国的福利体系的 建立与推广无法引起各界的重视。没有明确、规范的福利核算制度，福利核算也无从下手。

\subsection{ISEW应用的困难}

ISEW应用困难表现在三个方面：（1）虽然ISEW核算范围非常全面，从社会、政府、环 境多角度考量福利情况, 但ISEW指标本身也存在一些不足, 包括福利核算项目选取与计算方 法的设定有一定自由性不便于各国可比分析、同时作为衡量可持续性与福利度量指标的冲突 等; (2) ISEW 是由国外的学者提出的, 因此在构建我国ISEW时不能直接照搬初始ISEW核 算项目与方法, 要根据我国的经济状况作调整, 这也是应用一个困难之一; (3) 核算我国ISEW 所需的数据比较贵乏、没有建立完善的统计体系, 有些所需的核算数据只能通过市场调查或 采用一定方法估算取得，核算数据来源缺乏规范性与准确性。

\section{4. 建设中国可持续经济福利指数的建议}

\section{1 转变传统观念, 坚持可持续发展道路}

“唯GDP”这种传统的发展观念，不仅会让一些政府难以转变工作重心，忽视民生建设， 盲目地追求GDP数值增长, 甚至由于过分追求经济增长而造成严重生态破坏等环境问题。因 此, 要想构建中国可持续经济福利指数首先应打破 “唯GDP论” 的思想束缚, 然后以科学的、 可持续的发展观念引导政府与社会行动。可持续发展是指在满足当代人的需求情况下，不损 害后代人的利益满足其需求的发展。我国的科学发展观和构建社会主义和谐社会的发展战略 也充分地体现了这一思想。我国要坚定不移的走可持续发展道路, 以长远、持续的思想处理 经济增长与各个方面的关系，使得社会各界重视经济增长的效益与民生建设为我国构建可持 续经济福利指数打下良好的社会基础。 


\section{2 完善相关福利制度建设}

构建我国可持续经济福利指数首先要解决我国福利制度缺失问题。这里的制度缺失是指 保障与核算制度缺失。建立福利保障与核算制度不仅可以为我国ISEW的应用提供制度保障、 促进建立相应福利核算的统计体系、更能督促、规范各级政府的推行、应用福利核算。此外, 在建立福利核算制度时, 应该考量我国经济发展的实际情况, 建立与我国经济特征相适应的 福利核算项目与对应的核算方法, 这样才能使得可持续经济福利指数能够真正地显示我国经 济福利水平、适用于指导我国经济运行、以达到提升经济福利的目的。

\section{3 有计划、逐步推行可持续经济福利体系}

ISEW 是一种全新的经济福利的核算体系，在建立、推行时必定会与传统GDP核算体系有 摩擦。因此, 可以有计划、分步骤的推行可持续经济福利指标, 在初步建立核算体系后, 可 以将其率先在一部分地区进行试点, 这样能够将ISEW在实际应用中的困难直接反馈, 检验其 合理、可行性并及时作出相应的调整, 为之后全国的推广提供参考。这种边推行边修正的方 式才是最有效的推广我国可持续经济福利体系的方法。

\section{References}

[1] Herman E. Daly, John B.Cobb, For the common good. Beacon Press, pp. 443-507, 1994

[2] Beatriz E, Castaneda, An index of sustainable economic welfare(ISEW) for Chile, Ecological Economics, vol. 28, pp. 231-244, 1999

[3] Engelbert Stockhammer, Harald Hochreiter, Bernhard Obermayr, The index of sustainable econmic welfare(ISEW) as an alternative to GDP in measuring economic welfare, Ecological Economics, vol. 21, pp. 29-34, 1997

[4] Federico M. Pulselli, Mirko Bravi, Enzo Tiezzi, Application and use of the ISEW for assessing the sustainability of a regional system:A case study in Italy, Journal of Econimic Bhavior \& Organization, vol. 81, pp. 766-778, 2012

[5] Matthew Clarke, Sardar M.N.Islam, Diminishing and negative welfare returns of econmic growth:an index of sustainable economic welfare(ISEW) for Thailand, Ecological Economics, vol. 28, pp.13-26, 2004

[6] Philip A. Lawn, A theoretical foundation to support the Index of Sustainable Economica Welfare(ISEW), Genuine Progress Indicator(GPI), and other related indexes, Ecological Economics, vol. 44, pp. 105-108, 2003

[7] Max -Neef M, Economic Growth and Quality of Life: A Threshold Hypothesis, Ecological Economics, vol. 15, pp. 115-118, 1995

[8] Andrew John Brennan, Theoretical foundation of sustainable economic welfare indicators -ISEW and political economy of disembedded system, Ecological Economics, vol. 67.pp. 1-19, 2008

[9] Eric Neumayer, On the methodology of ISEW, GPI and related measures:some constructive suggestions and some doubt on the 'threshold' hypothesis, Ecological Economics, vol. 67,pp. 347-361, 2000 